\title{
Are tau aggregates toxic or protective in tauopathies?
}

\author{
Catherine M. Cowan* and Amrit Mudher* \\ Centre for Biological Sciences, University of Southampton, Southampton, UK
}

\section{Edited by:}

Jesus Avila, Centro de Biología

Molecular Severo Ochoa CSIC UAM,

Spain

Reviewed by:

Diego Rincon-Limas, University of

Florida, USA

Efthimios M. C. Skoulakis, Biomedical

Sciences Research Centre Alexander

Fleming, Greece

*Correspondence:

Catherine M. Cowan and Amrit

Mudher, Centre for Biological

Sciences, University of Southampton,

Building 85, Highfield Campus,

Southampton SO17 1BJ, UK

e-mail: c.m.cowan@soton.ac.uk;

a.mudher@soton.ac.uk
Aggregation of highly phosphorylated tau into aggregated forms such as filaments and neurofibrillary tangles is one of the defining pathological hallmarks of Alzheimer's disease and other tauopathies. Hence therapeutic strategies have focused on inhibition of tau phosphorylation or disruption of aggregation. However, animal models imply that taumediated dysfunction and toxicity do not require aggregation but instead are caused by soluble hyper-phosphorylated tau. Over the years, our findings from a Drosophila model of tauopathy have reinforced this. We have shown that highly phosphorylated wild-type human tau causes behavioral deficits resulting from synaptic dysfunction, axonal transport disruption, and cytoskeletal destabilization in vivo. These deficits are evident in the absence of neuronal death or filament/tangle formation. Unsurprisingly, both pharmacological and

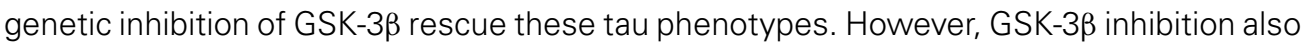
unexpectedly increases tau protein levels, and produces insoluble granular tau oligomers. As well as underlining the growing consensus that tau toxicity is mediated by a highly phosphorylated soluble tau species, our findings further show that not all insoluble tau aggregates are toxic. Some tau aggregates, in particular tau oligomers, are non-toxic, and may even be protective against tau toxicity in vivo. This has serious implications for emerging therapeutic strategies to dissolve tau aggregates, which might be ineffective or even counter-productive. In light of this, it is imperative to identify the key toxic tau species and to understand how it mediates dysfunction and degeneration so that the effective disease-modifying therapies can be developed.

Keywords: Alzheimer's disease, dimer, oligomer, filament, neurofibrillary tangle, insoluble tau

\section{INTRODUCTION}

\section{TAU PROTEIN IN ALZHEIMER'S DISEASE AND OTHER TAUOPATHIES}

Deposits of insoluble tau within neurons are defining pathological hallmarks in the group of neurodegenerative diseases known as tauopathies. Tauopathies include Alzheimer's disease (AD), Fronto-temporal Dementia with Parkinsonism on chromosome17 (FTDP-17), Pick's disease, Corticobasal Degeneration (CBD), Progressive Supranuclear Palsy (PSP), and others (1). In all of these conditions, tau becomes both abnormally hyper-phosphorylated and deposited in insoluble aggregates [reviewed in Ref. $(1,2)]$. These diseases differ in their clinical features, differentiallyaffected neuronal populations, and the distinct forms taken by the insoluble tau. Indeed, even within one disease state, the insoluble tau may be found in many distinct morphological forms; some en route to the final form of that disease's tau deposits, and others possibly on a different pathway.

In this review we will focus primarily on the forms of insoluble tau observed in $\mathrm{AD}$, since they have been more widely studied. We will describe the different species of insoluble tau that have been identified; briefly review the factors that might promote tau aggregation; and then assess the evidence for and against the toxicity of each type of tau aggregate. Inevitably, this cannot be a comprehensive account of the extensive literature on this subject in the interests of space. Therefore we have selected papers which we believe represent the balance of evidence for and against toxicity, with apologies to those whose work we have not included. In this context we will use the term toxicity rather broadly, meaning either neuronal death, or neuronal dysfunction without death.

\section{PHYSIOLOGICAL AND PATHOLOGICAL SPECIES OF TAU}

This section briefly describes the major forms that tau has been shown to take in AD. These different species are treated in approximate order of size, from smallest to largest (Table 1). However, there is no intention to imply that each one goes on to form the next in a clear pathway.

\section{MONOMER}

Monomers of tau are highly soluble proteins of $55-74 \mathrm{kDa}$ in size [depending upon splice variant and phosphorylation status - (3)]. There are six splice variants which contain either three or four microtubule-binding repeats, as well as either zero, one, or two $\mathrm{N}$-terminal domains. These isoforms are usually denoted $\operatorname{tau}^{0 \mathrm{~N} 3 \mathrm{R}}, \operatorname{tau}^{1 \mathrm{~N} 3 \mathrm{R}}, \operatorname{tau}^{2 \mathrm{~N} 3 \mathrm{R}}, \operatorname{tau}^{0 \mathrm{~N} 4 \mathrm{R}}, \operatorname{tau}^{1 \mathrm{~N} 4 \mathrm{R}}$, and $\operatorname{tau}^{2 \mathrm{~N} 4 \mathrm{R}}$. They usually acquire a predominantly random coil structure under normal physiological conditions (4). Partially folded forms of tau monomers have also been described which are distinct from native tau monomers, and have a reduced level of random coiling but an increased level of $\beta$-sheet structure (5). Interestingly, such molecules are immediately positive for Thioflavin (which binds $\beta$-sheet). Compact monomers have also been characterized displaying intra-molecular disulfide bonds (6). Only the three isoforms of four-repeat tau can form these compact monomers, since 
Table 1 | Summary of the major forms of tau identified.

\begin{tabular}{|c|c|c|}
\hline Species of tau & $\begin{array}{l}\text { Abnormally } \\
\text { phosphorylated? }\end{array}$ & Toxic? \\
\hline Monomer & Sometimes & $\begin{array}{l}\text { Probably only when aberrantly } \\
\text { phosphorylated }\end{array}$ \\
\hline Dimer/trimer & Sometimes & $\begin{array}{l}\text { Some types shown to be } \\
\text { sufficient for toxicity }\end{array}$ \\
\hline $\begin{array}{l}\text { Small soluble } \\
\text { oligomer }\end{array}$ & Sometimes & $\begin{array}{l}\text { Some types shown to be } \\
\text { sufficient for toxicity }\end{array}$ \\
\hline Granular Tau oligomer & Sometimes & Not always \\
\hline Filament & Yes & $\begin{array}{l}\text { Might comprise of toxic tau, } \\
\text { yet filaments themselves are } \\
\text { probably neither necessary } \\
\text { nor sufficient for toxicity }\end{array}$ \\
\hline Neurofibrillary tangle & Yes & $\begin{array}{l}\text { Might comprise of toxic tau, } \\
\text { yet tangles themselves are } \\
\text { probably neither necessary } \\
\text { nor sufficient for toxicity }\end{array}$ \\
\hline Ghost tangle & Yes & Unlikely \\
\hline
\end{tabular}

the second cysteine required for an intra-molecular interaction is in the extra repeat domain.

\section{DIMER/TRIMER}

Dimers are composed of two tau monomers in anti-parallel orientation linked by disulfide bonds. Tau dimers can be observed by electron microscopy (EM) as rod-like particles $22-25 \mathrm{~nm}$ long, which is similar in appearance to the monomers (7). Dimers can form from any isoforms of tau. Within that, however, two distinctly different forms of dimers have been described (8). One is cysteine-dependent and reducible; while in contrast the other is cysteine-independent, non-reducible, and has inter-molecular disulfide bridging at the microtubule-binding domain. Both forms have been identified in vitro, and in tau transgenic (JNPL3) mice (8). Preparing small oligomers from recombinant tau in vitro, dimers have been reported with apparent sizes of $180 \mathrm{kDa}$ (9) and $130 \mathrm{kDa}(10)$, as well as trimers with an apparent size of $120 \mathrm{kDa}(11)$. In human tau transgenic mice, soluble tau species of $140 \mathrm{kDa}$ have been described $(8,12)$. Small soluble tau species of approximately dimer and trimer size, and probably including tau fragments, have also been isolated from synapses in $\mathrm{AD}$ brains (13). It is unclear whether these variously reported dimers and trimers are indeed different tau species or whether they represent subtle variations of the same structure.

\section{SMALL SOLUBLE OLIGOMER}

Small soluble oligomers of tau of very many different sizes have been described in vitro and in vivo. Often, however (perhaps because of differences in post-translational modifications leading to different apparent sizes on PAGE), it can be difficult to determine if small oligomers described by different groups represent the same species or not. In one study, the soluble dimers described above were shown in vitro to develop into small soluble oligomers containing six to eight tau molecules (approximately $300-500 \mathrm{kDa}$ in size) (8). JNPL3 mice, which over-express human tau with the $\mathrm{P} 301 \mathrm{~L}$ mutation (tau ${ }^{0 \mathrm{~N} 4 \mathrm{R}-\mathrm{P} 301 \mathrm{~L}}$ ) and harbor neurofibrillary tangles (NFTs), additionally have small tau oligomers which run at a wide range of sizes by PAGE [Sahara et al. (8)].

\section{INSOLUBLE GRANULAR TAU OLIGOMER}

Granular tau oligomers (GTOs) are electron-dense granular or globular aggregates of tau. They have been isolated from AD brains, mostly at early and moderate Braak stages (14). GTOs are composed of an average of 40 densely packed tau monomers. This corresponds to a size of $1800 \mathrm{kDa}$, or $20-50 \mathrm{~nm}$ in diameter when observed by EM or by atomic force microscopy (AFM) (15). It is important to note that, on the scale of insoluble protein aggregates generally, this is extremely small. Standard protocols for the sedimentation of insoluble proteins, such as $100,000 \times g$ spin for 30-60 min [e.g., Ref. (16)], would fail to sediment GTOs which would remain in suspension in the "soluble" fraction, despite their demonstrable insolubility in SDS (15). Instead, sedimentation of GTOs requires a $200,000 \times g$ spin for $2 \mathrm{~h}$ (15). The same authors developed a rigorous fractionation/purification protocol for GTOs. They further characterized the GTOs as being positive for $\mathrm{MC} 1$ and for Thioflavin, despite clearly being not filamentous in any way. They conclude that GTOs have $\beta$-sheet structure, and suggest that they may be composed of the partially folded form of tau monomer (15).

\section{FILAMENT}

It is well known that tau is capable of polymerization into filamentous forms. In $\mathrm{AD}$, the predominant filaments are Paired Helical Filaments (PHF) and Straight Filaments (SF). In other tauopathies such as FTDP-17, however, there is variability in the morphology of tau filaments depending upon the tau mutations and/or tau isoforms involved. Here, filaments may take on other shapes such as twisted ribbon-like and rope-like filaments (17). A straight filament strand is $10 \mathrm{~nm}$ wide, and thus PHFs display alternating widths of 10 and $20 \mathrm{~nm}$, with a half-periodicity of $80 \mathrm{~nm}(18,19)$. Tau filaments exhibit $\beta$-sheet structure (20) which forms through the MT-binding repeat region $(7,21)$. Tau filaments from human $\mathrm{AD}$ brain have been shown to contain all six tau isoforms (22), although in vitro they can also be formed from single isoforms. They can be considered an amyloid $(23,24)$.

\section{PRETANGLE}

The pretangle is a slightly confusing concept that historically may have referred to a variety of species of tau, or even the status of a neuron. Generally speaking, a pretangle neuron is one that is positive for abnormal tau epitopes (misfolded and/or hyperphosphorylated), in some insoluble format large enough to be visible by light microscopy, yet free from mature fibrils or tangles by morphology. Bancher et al. (25) helpfully classified tangles into four stages $(0-3)$. In this system ${ }^{1}$, stage 0 tangles (later referred to

\footnotetext{
${ }^{1}$ For reference, stage 1 in this system is filamentous silver-stained tangles composed primarily of PHF; stage 2 is a classic neurofibrillary tangle and stage 3 is a ghost tangle (See "Neurofibrillary Tangle" and "Ghost Tangle").
} 
by others as pretangles) are identified by cytoplasmic non-fibrillar (granular or diffuse) tau immunoreactivity, visible at the light microscope level. When viewed by EM, the labeled material was found to consist of PHFs, SFs, and smaller granular electron-dense material. Where pretangles were observed as granular via light microscopy, this probably represents non-filamentous clumps of PHFs, SFs, and the ultrastructural granules. Other researchers have described immunoreactivity for certain abnormal AD-associated tau epitopes in neurons containing no fibrils, and have deemed the neurons so labeled to be at a pretangle stage [for example Alz50 (26), the 12E8 epitope S262/S356 (27,28), and T231 (27,29)]. Confusingly, there are a number of conflicting reports in the literature as to whether "pretangles" are silver-staining, thioflavin-positive, and whether or not they contain $\beta$-sheet structure. It seems probable that these discrepancies arise from (a) a heterogeneity of what is meant by "pretangle" and (b) a sensitivity issue in regard to the assays for $\beta$-sheet. Pretangles should surely be positive for markers of $\beta$-sheet, since even the earliest partially-folded monomer (5) and certainly tau filaments (30) demonstrably contain $\beta$-sheet structure.

\section{OTHER LARGE NON-FIBRILLAR TAU AGGREGATES}

There are other forms and morphologies of pathological insoluble tau found in human brains which are large enough to be seen with the light microscope, and may be filamentous, yet are non-fibrillar in structure. Such aggregates include Hirano bodies, Pick bodies, and argyrophilic grains.

Hirano bodies have been described in AD, Pick's disease and other tauopathy brains $(31,32)$. Hirano bodies are large intraneuronal paracrystalline structures of $5-10 \mu \mathrm{m}$ in width by $10-30 \mu \mathrm{m}$ in length, composed of $7 \mathrm{~nm}$ filament arrays (32). They contain tau, other microtubule-associated proteins, actin, cofilin, other actin-binding proteins, and a fragment of APP.

Pick bodies are the characteristic morphology assumed by tau filaments in Pick's disease, in which they accumulate in limbic and cortical neurons. They are large structures that vary in size in different neuronal types, but are approximately the size of the nucleus. Pick bodies are formed of disorganized bundles of filaments which comprise only the three 3-repeat isoforms of tau, in contrast to the PHFs and SFs formed in $\mathrm{AD}$ which are made of all six isoforms [reviewed in Ref. (33)].

Argyrophilic grains are found in Argyrophilic Grain disease, where they accumulate in both neuronal processes and oligodendrocytes (34). Argyrophilic grains are structures that may be spherical, oval, comma-shaped, or spindle-shaped. As the name suggests, they are readily detectable by conventional silver-staining and light microscopy. The grains are much smaller than Hirano bodies, Pick bodies, and NFTs at approximately $4-9 \mu \mathrm{m}$ in size. Argyrophilic grains are comprised of four-repeat tau in 9-18 nm SF and bundles of $25 \mathrm{~nm}$ smooth tubules. They never contain PHFs and ribbon-like filaments (34-36).

\section{NEUROFIBRILLARY TANGLE}

Neurofibrillary tangles are the classic tangles first described by Alzheimer in 1907. Classified by Bancher et al. (25) as stage 2 tangles and often described as "flame-shaped," they are large bundles of fibers consisting of both PHFs and SFs which may fill the entire neuronal cytoplasm. The fibers are silver-staining. Brief mention should be made here also of neuropil threads, which are bundles of SFs and PHFs occupying dendrites and largely displacing the cytoskeleton (37).

\section{GHOST TANGLE}

Ghost tangles are the structures that remain when the neuron within which the tangle formed has degenerated. They comprise large extracellular bundles of loosely arranged tau filaments. Compared to NFTs, ghost tangles stain more weakly for tau and more strongly for ubiquitin (25). It is thought that ghost tangles have undergone substantial proteolysis, and that thus the filaments are comprised predominantly of tau fragments, again in contrast to NFTs (38).

\section{THE SEQUENCE OF EVENTS IN TAU AGGREGATION}

There is some evidence to suggest that larger tau aggregates like PHFs and NFTs evolve from the successive aggregation of smaller tau species like monomers and soluble oligomers (Figure 1). One missing link appears to be whether small oligomers can form directly into GTOs in a linear pathway, or whether they represent two different pathways from monomers to PHFs and NFTs.

\section{MONOMER $\rightarrow$ DIMER}

There is evidence from the kinetics of tau polymerization that, once the partially folded conformation of the monomer has formed (however that may be triggered), then the process from monomers to dimers (and thence to oligomers) is energetically favorable and proceeds spontaneously (5). For monomers to be able to form dimers requires the PHF6 hexapeptide in the third microtubule-binding repeat domain $(8,39)$. However, the compact form of the tau monomer does not participate in this form of aggregation (40).

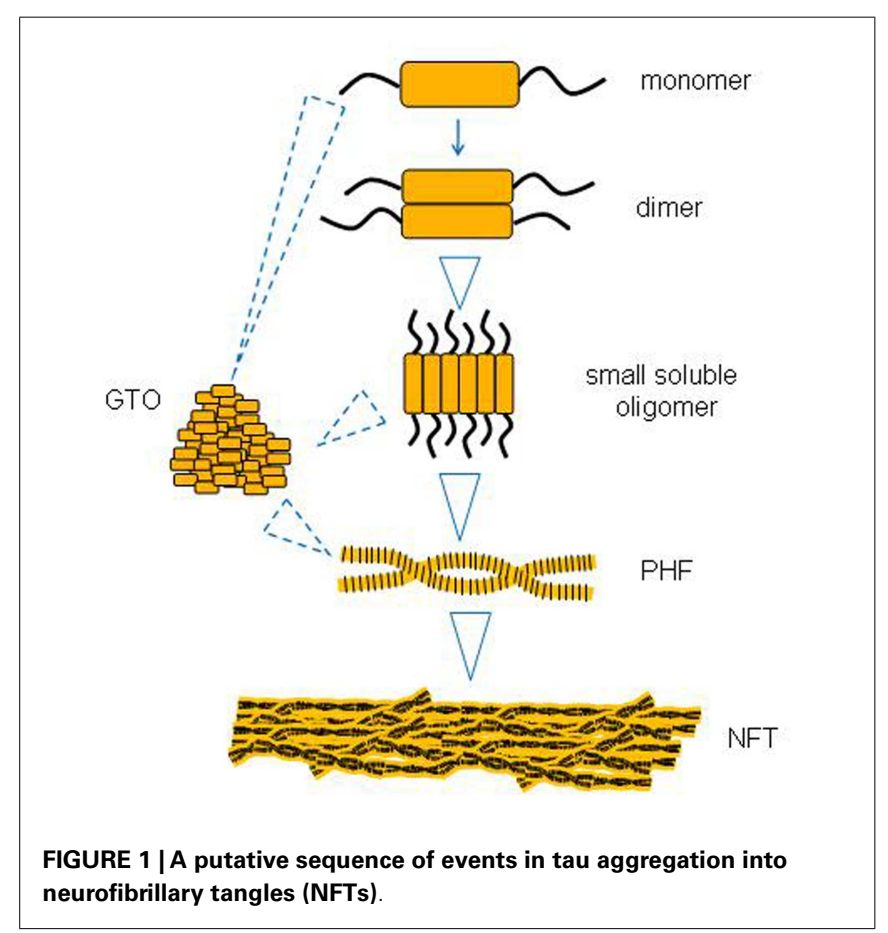




\section{DIMER $\rightarrow$ SMALL SOLUBLE OLIGOMER}

The tau dimer, in particular the cysteine-independent, nonreducible form (8), is thought to be an important intermediate which is involved in controlling the rate of formation of larger intermediates and fibrillization $(6,7,41)$. In addition, more than one group has demonstrated that in vitro generated tau dimers aggregate to form larger tau oligomers $(8,9)$.

\section{SMALL SOLUBLE OLIGOMER $\rightarrow$ GTO}

We are not aware of any direct evidence that small oligomers proceed to form GTOs. There is, however, evidence that tau monomers in vitro can form GTOs (15), as well as that both monomers and GTOs can form PHFs. However, whether the sequence always proceeds from monomer $\rightarrow$ dimer $\rightarrow$ small oligomer $\rightarrow$ GTO $\rightarrow$ filament, or whether GTOs and other types of tau oligomers can be on different pathways, is not clear. In general, it is believed that when tau forms larger structures such as filaments of differing morphology, the interactions between tau molecules remain the same, and subunit packing follows the same plan (40). On these grounds it is plausible that GTOs might be part of the same pathway.

\section{GTO $\rightarrow$ PHF}

Increasing the concentration of GTOs in vitro causes them to form filaments, whereas the constituent soluble tau does not. On the basis of this, it is suggested that GTOs are precursors of PHFs (15).

\section{MONOMER/DIMER $\rightarrow$ PHF (POSSIBLY VIA THE OTHER INTERMEDIATES)}

There is a wide variety of evidence showing that monomers can polymerizes into PHF, but that does not address whether this is via the oligomeric intermediates or not. Such evidence includes the early in vitro demonstrations that tau at high concentrations will self-assemble into PHFs (42-44), and evidence that dimers are normally rate-limiting intermediates in this process in vitro $(4,6)$. There followed from these studies a large body of work delineating important details such as which motifs within tau are required for fibrillization, in which monomeric tau clearly formed into PHFs $(39,45-47)$. However, as in the early studies, whether oligomers were formed on the way was not necessarily assessed directly.

The mechanism for PHF formation requires two hexapeptide motifs in the microtubule-binding region of tau. These are PHF6 [(306)VQIVYK(311)] and PHF6* [(275)VQIINK(281)]. Formation of PHFs involves these two motifs changing conformation from random coil to $\beta$-sheet structure $(24,39)$. It should be noted that mutant tau containing no cysteines is still able to form PHFs in vitro, even though much more slowly than WT tau (40). This means that cysteine-dependent (covalent) dimers are not a requisite stage between monomer and PHF.

\section{PHF $\rightarrow$ NFT}

It is well established that NFTs in vivo are composed of PHFs and SFs (25). Furthermore, there is also direct in vitro evidence that filaments will spontaneously clump together into NFTs (48). Thus it is highly likely that NFTs are formed by the accumulation of tau filaments.

\section{WHAT PROMOTES TAU AGGREGATION?}

Little is known about what first triggers the initiation of tau aggregation. It is known that normal monomers do not spontaneously seed aggregation, and that some sort of trigger is needed $(30,49)$. However, numerous factors have been identified that can promote or increase tau aggregation, at least in vitro [reviewed in Ref. (50)].

Enzymatic cleavage of the tau monomer is one such factor. Truncation of the tau protein at Glu391 $(51,52)$, truncation by caspases at Asp421 (53), cleavage by thrombin (54), removal of the C terminus of the protein $(55,56)$, or deamination at asparagine or glutamine residues (57) have all been shown to promote tau aggregation [Reviewed in Ref. (58)].

Local concentration of tau can be key. Tau at high concentrations in vitro forms PHFs (42-44). Moreover, the transition of tau from random coil to $\beta$-sheet is also known to be concentration dependent (39), further supporting the idea that excessive local accumulation of tau may promote its aggregation (especially if other pro-aggregating factors - such as those discussed below - are also in the near vicinity).

Controversially, tau phosphorylation has been postulated to both stimulate and repress its subsequent aggregation into filaments. Circumstantial evidence for stimulation includes the seminal fact that filamentous tau is highly hyper-phosphorylated (59) at many sites. More direct but in vitro evidence shows that tau phosphorylated at $\mathrm{AD}$ sites polymerizes more readily into tangles of PHF/SF; dephosphorylation abolishes tau's self-assembly; and hyperphosphorylation of recombinant tau by brain kinases induces its self-assembly into tangles of PHF/SF $(60,61)$. In a cellular model, it has been shown that all three kinases GSK-3 $\beta$, MEKK, and JNK3 are required for tau aggregation (62). Phosphorylation of tau specifically at Thr231, Ser396, Ser422, and Ser404 promotes self-aggregation of tau into filaments $(55,63,64)$. In vivo, overexpression of the kinases GSK-3 $\beta$ or Cdk5 can promote tau aggregation $(65,66)$. On the other hand, in vitro studies have shown that tau phosphorylation is not necessary to drive tau into PHFs $(41,67)$. On the contrary, phosphorylation of KXGS motifs in the repeat region inhibits tau aggregation in vitro $(54,68)$. Furthermore, more recently emerging data showing that tau aggregates made up of recombinant non-phosphorylated tau can "seed" further tau aggregation in cells (discussed below) also supports the idea that phosphorylation is not required to promote aggregation $(69,70)$. However, it is not yet known whether phosphorylated tau would seed and promote aggregation at a different rate.

Some of the missense and deletion mutations found in tau in cases of fronto-temporal dementia (FTDP-17), when expressed in models, display enhanced aggregation compared to normal tau. In vitro PHF formation is faster for recombinant tau harboring one of various such mutations. Human tau with each one of the point mutations G272V, N279K, V337M, or R406W shows significantly faster in vitro PHF formation than WT full-length human tau, while the $\Delta \mathrm{K} 280$ and P301L mutants form PHFs at dramatically greater speeds (46). This phenomenon has been confirmed in vivo: mice expressing mutant human tau ${ }^{\mathrm{P} 301 \mathrm{~L}}$ develop pathology more readily than those expressing WT human tau, both on ON4R and 2N4R tau backgrounds (71-73).

Many polyanionic cofactors of all kinds can promote $\mathrm{PHF}$ assembly. These include glycosaminoglycans (GAGs) such as 
heparin and neuroparin (40, 74, 75); sulphoglycosaminoglycans (sGAGs) like keratins or chondroitin sulfates (76), RNA (41); polyglutamic acid $(30,41,74)$; fatty acids such as arachadonic acid $(77,78)$ and alkyl sulfate detergents (79).

Other factors which may promote tau aggregation include tissue transglutaminase (80), Congo red (81), ferritin (82), $\mathrm{H}_{2} \mathrm{O}_{2}$ in the presence of iron (Fenton's reaction) (83), and quinones (84).

Despite this wealth of data over many years regarding factors that promote aggregation, questions still remain about what initiates tau aggregation in vivo in health and disease. However, once tau aggregation has been initiated, it is believed to promote further "prion"-like "seeding" and propagation of tau aggregation and pathology (85). This was first demonstrated in vivo where stereotaxic injections of brain homogenate containing tau aggregates led to induction and propagation of tau aggregation in tau transgenic mice (85). Supportive data also emerged from studies in cell culture showing that incubation of tau-expressing cells with fibrils of recombinant tau leads to induction of tau aggregation in the recipient cells $(69,70)$.

\section{ARE NEUROFIBRILLARY TANGLES TOXIC? \\ NFTs: EVIDENCE FOR TOXICITY}

The evidence that associates NFTs with neuronal dysfunction and neurodegeneration is largely correlative in nature. Studies of human post-mortem brains initially implicated NFTs in toxicity by showing a strong spatial and temporal correlation between NFTs and severity of dementia, and between NFTs and neurodegeneration or neuronal death (86-92). Some tau transgenic mouse models display neuron loss in the same timeframe and/or location as NFT formation. For example, expression of tau ${ }^{\mathrm{P} 301 \mathrm{~L}}$ under the thy1.2 promoter causes neuronal apoptosis at the same age as filaments and NFTs (93); while tau ${ }^{\mathrm{P} 301 \mathrm{~L}}$ under the prion promoter causes NFTs in spinal cord, brainstem, and pretangles in cortex, at the same time as loss of motor neurons (71). Furthermore, in tau mouse models, there is a correlation between reduction of NFT and improvement in cognition (94). The limitation of these correlative studies between reduced NFTs and reduced impairments is that, in many cases, other smaller tau species may be reduced also. This leaves open the question of whether it is the reduction of the NFTs or the smaller species which has been beneficial.

More direct evidence in favor of NFT toxicity comes from mice conditionally expressing human tau fragments harboring pro-aggregation or anti-aggregation mutations (95, 96). Proaggregation mice develop PHFs, "pretangles," and NFTs early; followed by synaptic and neuronal loss. In constrast, mice expressing the same tau molecule but with the anti-aggregation mutation never develop aggregates or neuronal pathology. This was verified in a C. elegans model of tauopathy which went further to show that treatment with anti-aggregation inhibitors protected against taumediated toxicity (97). This suggests that tau aggregation in the form of PHFs or larger has been the cause of cell death. Moreover, when expression of human tau is suppressed, mice are rescued from toxicity in terms of both cell death and cognition. This represents very strong evidence in favor or PHFs and/or NFTs as the toxic species. These conclusions were difficult to reconcile with a body of evidence detailed below proving that PHFs and NFTs are neither necessary nor sufficient for toxicity. However, the authors subsequently showed that in the animals expressing pro-aggregant tau, toxicity might in fact be mediated by a species of tau smaller than PHFs and NFTs $(98,99)$.

\section{NFTs: EVIDENCE AGAINST TOXICITY}

There is now strong evidence from a number of models that NFTs are not required for tau-induced neuronal dysfunction and toxicity. In most Drosophila models of tauopathy, neuronal NFTs are usually not formed at all, despite clear neurodegeneration, and functional phenotypes (100-104). In some mouse models where NFTs do form, cognitive/behavioral impairments and cell death can be demonstrated earlier in the time course of the disease prior to NFT formation (105). In a different mouse model [PrP44: the shortest human tau isoform $\left(\operatorname{tau}^{0 \mathrm{~N} 3 \mathrm{R}}\right)$ under the prion promoter] the formation of tau filaments coincides in the time course of the disease with phenotypes such as neurodegeneration and motor deficits, while NFTs form later $(106,107)$.

There is also compelling evidence that NFTs are not sufficient for toxicity, from mice that conditionally express human tau $\left(\mathrm{tau}^{\mathrm{ON} 4 \mathrm{R}-\mathrm{P} 301 \mathrm{~L}}\right)$. These mice display age-dependent development of NFTs, neuronal loss, and progressive motor deficits. When tau expression is switched off after the onset of memory impairments and NFT formation, memory improves and cell loss is stabilized, yet NFTs remain $(108,109)$. Furthermore, when tau is turned off at a timepoint when there are pretangles but no NFTs yet, the pretangles stay stable. This indicates that they also are insufficient for toxicity. This is corroborated in a different study using the same mice, in which a successful treatment reduced motor deficits despite failing to reduce NFTs (110). Furthermore, tanglebearing neurons in this model were shown to be just as active in a functional hippocampal circuit as non-tangle bearing neurons (as evidenced by expression of the immediate early gene Arc in response to environmental cues) (111). Further investigations of the mouse conditionally expressing pro- and anti-aggregant form of tau, mentioned in the preceding section, also supports this view. The pro-aggregation mice develop learning and memory deficits from which they recover after tau expression is turned off (98). However, it transpires that after an extended period of tau suppression, NFTs still remain, as in the tau ${ }^{0 \mathrm{~N} 4 \mathrm{R}-\mathrm{P} 301 \mathrm{~L}}$ mice. This implies that it is a smaller species of tau (soluble or insoluble) which has decreased in correlation with behavioral improvement in these studies (98).

In the light of such evidence, it has been suggested that formation of NFTs is a protective response that ultimately fails (58). This review describes a scenario in which caspases, having become activated because the cell contains toxic tau and is thus under stress, cleave the tau making it more fibrillogenic. Cleavage is unlikely to be the only trigger, since the initial steps of aggregation can involve primarily full-length tau isoforms $(5,112)$. Either way, the idea is that once tau aggregates seed, they can sequester toxic tau and thus delay cell death. However, the trade-off is that axonal transport is compromised and cellular protein degradation pathways become clogged, and thus the neuron gradually becomes dysfunctional (58). This is supported by evidence that NFT-bearing neurons appear to survive for decades (113) and maintain markers of normal gene expression (111), and may be in fact be longer lived than 
those neurons without NFTs in the AD brain that would have died at earlier time-points and hence were not evident at post-mortem.

In conclusion, despite NFTs being a vital historical clue to the involvement of tau in neurodegenerative disease, a wide variety of strong evidence now exists that NFTs themselves are neither necessary nor sufficient to cause tau-induced toxicity and dysfunction.

\section{ARE TAU FILAMENTS TOXIC?}

Some of the evidence regarding NFTs is also applicable as indirect evidence about tau filament toxicity. That is, some of the evidence in favor of large aggregates being toxic could really apply to either NFTs or PHFs/SFs or both. Further, the evidence that NFTs are not toxic naturally casts suspicion onto smaller pathological species such as filaments. However, direct evidence for PHFs as the primary toxic species, rather than something smaller, is sparse.

\section{FILAMENTS: EVIDENCE FOR TOXICITY}

As with the evidence in favor of NFT toxicity described above, much of the evidence that implicates filaments as a toxic species of tau is correlative in nature. For example, in some mouse models of tauopathy, filaments coincide in the time course of the disease with phenotypes such as neurodegeneration and motor deficits (106), while NFTs form later (107). Similar results were seen in one Drosophila model of tauopathy in which tau filament formation was reported (114). Furthermore, mutations in tau which are responsible for FTDP-17 also promote faster tau filament formation (46), thus circumstantially implicating tau filaments in the disease process.

An immunotherapy study targeting tau in a mouse model provided some more direct evidence in favor of PHF toxicity. In this study, immunization of JNPL3 mice (with a short phosphorylated tau fragment) served to reduce tau aggregation (into PHFs or larger aggregates) and the associated behavioral phenotypes, but failed to reduce smaller species of tau. This suggests that that PHFs or larger tau aggregates are the toxic species in this model (115). In another study, tau filaments but not monomers (at physiological concentrations) were shown to selectively impair anterograde transport in isolated squid axoplasm $(116,117)$.

\section{FILAMENTS: EVIDENCE AGAINST TOXICITY}

As with the NFT situation, some animal models have impairment but no filaments, or at least not until later in the disease progression. For example, Drosophila (100-104) and C. elegans (118) expressing human tau display behavioral phenotypes indicative of neuronal dysfunction and toxicity without forming tau filaments or larger aggregates. Even in mice, in the transgenic tau model expressing the longest human tau isoform ( $\left.\operatorname{tau}^{2 \mathrm{~N} 4 \mathrm{R}}\right)$, brains contain some form of insoluble tau but nothing as big as PHFs (or NFTs), while the animals display a motor impairment (119). Such evidence indicates that filaments are not necessary for tau-induced toxicity.

There is also evidence that filaments are not sufficient for toxicity, since they continue to form in the conditional tau mice mentioned earlier, in which transgenic tau expression has been turned off and deficits thereby rescued (108). In another mouse model, Andorfer et al. showed that, while there was widespread neurodegeneration, the PHF-containing neurons appeared "healthy" in terms of nuclear morphology, suggesting that the polymerized protein was probably neuroprotective (105). In an in vivo lamprey model (120), administration of a benzothiazole derivative drug (purported to break up tau filaments) successfully improved tau-induced phenotype, but apparently did so without actually breaking up the tau filaments. This provides further evidence that filaments are not sufficient for toxicity. In vitro, polymerization of hyper-phosphorylated tau into PHFs abolishes its toxic activity to sequester other MAPs (121). Unlike the soluble form of hyperphosphorylated tau, the filamentous form of tau does not bind MAPs and does not disrupt microtubules in vitro (121).

In an inducible cell line, the repeat domain of wild-type tau was non-toxic, whereas a similar construct harboring a point mutation that induced aggregate formation (eventually PHFs) caused cell death (54). Crucially, however, increased cell death was observed before PHF formation in the aggregate-prone mutant, demonstrating that PHFs were not necessary for toxicity, and that in fact a smaller form of aggregate was the toxic species.

While the in vivo evidence is not quite as extensive as for NFTs, one can also conclude that tau filaments are neither necessary nor sufficient for tau-induced toxicity, and that something smaller than filaments is the most toxic form of tau.

\section{SPECIES OF TAU FOUND IN FILAMENTS}

When the insoluble protein fraction from brains of AD patients or animal models, containing any tau filaments or larger tau aggregates, is solublized using urea or formic acid, the tau species which were building blocks of these large insoluble aggregates can be identified. These species include monomers of 55,60, 64, and $68 \mathrm{kDa}$ in size (67), and a $170-\mathrm{kDa}$ species. The 64 and $170 \mathrm{kDa}$ species in particular have been implicated in toxicity. The $64-\mathrm{kDa}$ species represents a hyper-phosphorylated monomer. It is found in brains of the tau ${ }^{0 \mathrm{~N} 4 \mathrm{R}-\mathrm{P} 301 \mathrm{~L}}$ transgenic mouse (122), and increases with age in the insoluble fraction at the expense of the $55-\mathrm{kDa}$ monomer (which is found in both soluble and insoluble fractions).

In the same study that showed NFTs were not necessary for toxicity [because they did not decrease in successfully treated tau mice - (110)], the successfully treated mice displayed a significant reduction in $64 \mathrm{kDa}$ tau from the high-speed insoluble fraction. Confusingly, subsequent commentators have described this species as "soluble aggregated tau" [e.g., Ref. (123)]. However, this $64 \mathrm{kDa}$ species is always a component of an aggregate that sediments at $150,000 \times g$, which is therefore bigger than a GTO. Another study in a conditional mouse model found that three distinct tau species correlated with neuronal dysfunction (12). Two of these species were in a sarkosyl-insoluble fraction (from which NFTs had been previously cleared) which must represent GTOs or filaments: a $64-\mathrm{kDa}$ hyper-phosphorylated monomer and a $170-\mathrm{kDa}$ hyper-phosphorylated oligomer. The third species was a $140-\mathrm{kDa}$ oligomer from the soluble fraction. All of these species arose early in the disease progression, and increased with increasing learning and memory deficits. Conversely, all three decreased upon suppression of transgenic tau expression and recovery from neuronal dysfunction. These results clearly implicate one or more of the three species in toxicity; however, it is not clear whether the culprit is the soluble or insoluble components or both. The same $64 \mathrm{kDa}$ species has also been described in a sarkosyl-insoluble 
fraction from transgenic tau ${ }^{0 \mathrm{~N} 4 \mathrm{R}-301 \mathrm{~L}}$ mice that represents $\mathrm{SF}$ and NFTs $(71,108)$. It is not toxic in this circumstance because it continues to increase after tau expression has been turned off and animals are recovering (108).

In summary, these two species of tau, a hyper-phosphorylated $64 \mathrm{kDa}$ monomer and a $170-\mathrm{kDa}$ oligomer, have frequently been demonstrated as components of an insoluble filament fraction. There is some evidence, although not conclusive, that these species may be associated with toxicity.

\section{ARE (INSOLUBLE) GRANULAR TAU OLIGOMERS TOXIC?}

Part of the difficulty in acquiring evidence about GTOs from the existing literature is that, as mentioned earlier, in standard insoluble protein fractionation protocols any GTOs in the sample will be lost. Even though fully insoluble, they are too small to sediment with a standard "high-speed insoluble" fraction (15). They remain in suspension in the "soluble" fraction; and yet as they are around $1800 \mathrm{kDa}$ in size and not readily reducible without $8 \mathrm{M}$ urea, they will not enter a standard PAGE resolving gel and be detected (Cowan, unpublished observation). Therefore when one reads, for example, studies in tau mouse models showing small oligomers and PHFs and drawing conclusions about toxicity, one cannot usually conclude anything about the presence or absence, toxicity or otherwise, of GTOs.

\section{GTOS: EVIDENCE FOR TOXICITY}

In the years following the identification of GTOs, when evidence was beginning to accumulate that PHFs and NFTs might not be toxic, some evidence remained that some insoluble form of tau must be toxic. There was speculation in reviews that insoluble oligomers of tau, perhaps GTOs, might be the most toxic species. However, there is no direct evidence for this. Clues that GTOs might be associated with toxicity come from studies showing that numbers of GTOs increase with progression of $\mathrm{AD}$, that fewer GTOs are observed at Braak stage 0 than at stage 1 , and that their peak precedes that of NFTs (14). GTOs are generally believed to consist of toxic phosphorylated species of tau because phosphorylated tau levels are high in the AD brain at the time-points when GTOs are abundant. Such clues have led to the suggestion that reducing GTOs may prove to be a promising therapeutic strategy; however, the authors of these publications acknowledge that the effect of GTOs on neuronal vulnerability is unknown.

There is also evidence that an insoluble oligomer(s) of some sort is probably the culprit, without clear evidence that it is GTOs. For example, in the study mentioned as evidence against PHF toxicity in an inducible cell line (54), the soluble tau construct was not toxic, whereas the aggregate-prone mutant tau species caused cell death prior to PHF formation. This therefore represents evidence against both soluble tau toxicity and PHF toxicity, but rather implicates some intermediate species. Similarly, in another study, very small insoluble tau oligomers (of up to a few hundred $\mathrm{kDa}$ ) were isolated from synaptosomes derived from $\mathrm{AD}$ brains and were associated with impaired ubiquitin proteasome function (124). If any GTOs had been present in this preparation, they might not have been observed with the protocols used. Clearly small insoluble tau oligomers exist and are associated with toxicity but whether they can be classified as GTOs or indeed their precursors is not clear.

\section{GTOS: EVIDENCE AGAINST TOXICITY}

We have recently observed, in a Drosophila model of tauopathy, the formation of GTOs which are non-toxic (125) When flies express human tau ${ }^{0 N 3 R}$ in neurons they exhibit a clear behavioral phenotype, but no insoluble tau. However, upon pharmacological or genetic manipulations which inhibit GSK-3 $\beta$, the phenotype is rescued and GTOs are produced. We demonstrate that these GTOs produced in flies are the same size as those isolated from human brain and comprise of non-phosphorylated full-length tau monomers. Like us, another group has also demonstrated the formation of large insoluble tau oligomers in Drosophila, in conditions associated with rescue of tau-mediated toxicity (126). They showed that rescue of human $\operatorname{tau}^{0 \mathrm{~N} 4 \mathrm{R}}$ or $\mathrm{tau}^{0 \mathrm{~N} 4 \mathrm{R}-\mathrm{R} 406 \mathrm{~W}}$ induced neurodegeneration and behavioral deficits by co-expression of Nicotinamide mononucleotide adenylyltransferase (NMNAT) also led to increased formation of insoluble tau oligomers. However whether these insoluble tau oligomers were the same as the GTOs that we described in our model is not clear. Nonetheless, both our studies collectively imply that tau aggregation can correlate with rescue from tau-induced phenotype. However, whether this is because of sequestration of smaller toxic tau species, or the presence of non-phosphorylated tau in the conditions in which the GTOs form, or something else about their structure is not clear.

Overall, the pathological significance of GTOs has yet to be fully understood. It is possible that different GTOs form in different circumstances and the phosphorylated status of their constituent tau proteins and/or the extent of $\beta$-sheet structure may play a role in determining their toxicity.

\section{ARE SOLUBLE (MONOMERIC OR OLIGOMERIC) TAU SPECIES TOXIC?}

As has already been alluded to, there are numerous species of tau that are soluble, and it seems probable that they possess very different properties. Just considering monomers, there is clearly a multiplicity of species: the three major conformations described (regular, compact, and partially folded); the six splice variants; and of course the array of phosphorylation combinations, both demonstrated and possible, which have been barely touched upon here. Then there are at least two conformations of dimer (cysteine-dependent and independent), as well as trimers, and small oligomers of various sizes and phosphorylation states, as described earlier. We would speculate that there are probably many variations of soluble oligomeric tau species occurring in nature in the brain that have not yet been specifically described. Further, some of the evidence regarding the toxicity or otherwise of soluble tau cannot (or did not) differentiate between these species.

\section{SOLUBLE TAU: EVIDENCE FOR TOXICITY}

There are many examples of studies conducted in vivo and in vitro showing that soluble tau is sufficient to cause dysfunction and toxicity. To give a few examples, pseudophosphorylated tau causes cell death when virally expressed in hippocampal slices, without becoming SDS-insoluble (127). Soluble tau monomer applied 
extracellularly to cells in culture causes intracellular calcium increase and cell death $(128,129)$. Additionally, some tauopathy models in Drosophila (100-102, 130) exhibit significant neuronal dysfunction and degeneration and yet contain no insoluble tau providing strong evidence that soluble tau is sufficient to cause dysfunction and toxicity. Similar evidence exists in mouse models: for example, mice expressing WT tau ${ }^{2 \mathrm{~N} 4 \mathrm{R}}$ under the CamK-II promoter (131) as well as those expressing mutant tau ${ }^{\mathrm{N} 279 \mathrm{~K}}(132)$ both display learning defects but no NFTs or insoluble tau and no cell death. However, these mouse studies are subject to the caveat discussed in Section "Are (Insoluble) Granular Tau Oligomers (GTOs) Toxic?" that if there were any GTOs present they would not have been detected by the protocols used. Therefore, strictly speaking, we feel that the conclusion from such studies is: either soluble tau or small insoluble tau oligomers are sufficient for toxicity.

Further evidence supporting soluble tau toxicity comes from many studies showing rescue of tau-mediated phenotypes after suppression of tau expression which leads to reductions in soluble tau but persistence of tangle pathology $(58,108,111,133)$. In one such study, transgenic tau ${ }^{\mathrm{P} 301 \mathrm{~L}}$ mice were treated with methylene blue at a dose sufficient to rescue their memory deficit, and reduce total and soluble tau without affecting insoluble tau aggregates (134). This study went one step further in showing that the reduction of soluble tau is required for the rescue of phenotype.

Whether the toxic soluble species of tau is monomeric or oligomeric (or both) in these studies is not always clear. There is a convincing body of evidence showing that certain specific dimers, trimers, and other very small soluble oligomers are sufficient to cause toxicity both in vitro and in vivo. Patterson et al. (135) show that the $180-\mathrm{kDa}$ dimers that they produced in vitro can suppress fast axonal transport in a squid axoplasm model. The $120-\mathrm{kDa}$ trimers produced by Lasagna-Reeves et al. have been shown to be toxic in vitro (11) and in vivo (136). These trimers cause significantly more cell death than tau monomers or filaments when applied to SH-SY5Y cells in culture (11). Intra-hippocampal injections of trimers cause significant loss of synapses and neurons resulting in memory deficits, whereas injections of tau monomers or fibrils do not (136). Overall, these findings show that dimers and trimers of tau can be toxic.

Tau species of this size range have also been demonstrated in vivo, indicating that they are physiologically relevant. Both the Kayed and the Binder laboratories have used the oligomers that they made in vitro to raise oligomer-specific anti-tau antibodies, TOC-1 (9) and T22 (137), which they demonstrate recognize tau in situ in the post-mortem AD brain. Both oligomerspecific antibodies react with "pretangles" in early Braak stages, and co-localized with some disease-associated phospho-tau epitopes.

Small soluble oligomers also arise in many transgenic tau animal models in a context that implicates them in toxicity. For example, transgenic Drosophila expressing either human tau ${ }^{0 N 4 R}$ or tau ${ }^{0 \mathrm{~N} 4 \mathrm{R}-\mathrm{S} 406 \mathrm{~W}}$ in brain display soluble tau oligomers of 150$250 \mathrm{kDa}$ in size $(114,126)$ and in both studies oligomer formation was associated with degeneration. Berger et al. (12) and Sahara et al. (8) independently identified small soluble tau oligomers of approximately $140 \mathrm{kDa}$ (believed to be dimers) in brain homogenates of tau ${ }^{0 \mathrm{~N} 4 \mathrm{R}-\mathrm{P} 301 \mathrm{~L}}$ transgenic mice. The oligomers detected by Berger et al. (12) (in the inducible tau ${ }^{0 N 4 R-P 301 L}$ mice) appeared at very early stages of disease when memory deficits were evident in the absence of tangle formation or neuronal loss. Either this $140 \mathrm{kDa}$ soluble species and/or the two small insoluble species of tau discussed in Section "Species of Tau Found in Filaments" are implicated in causing toxicity in this model.

Like the oligomers identified by the Binder and Kayed laboratories described above, the $140-\mathrm{kDa}$ oligomers identified by Berger et al. (12) in tau transgenic mice are also detectable in the brains of $\mathrm{AD}$ and FTDP-17 patients. It is not clear whether all of these oligomers are one and the same tau multimer or whether they represent tau oligomers at different stages of maturation during the disease process. In addition, it has not been determined whether aggregation into larger oligomers alters the toxicity of the small tau oligomers.

\section{SOLUBLE TAU: EVIDENCE AGAINST TOXICITY}

Evidently, not all soluble phosphorylated tau can be toxic. Soluble tau of many species is obviously found physiologically in healthy individuals. One specific example of a soluble species known to be non-toxic is the compact monomer with intra-molecular disulfide bonds, which appears to be a species that is relatively protective and, notably, does not go on to form larger aggregates (40).

In the tau immunization study mentioned earlier as evidence in favor of PHF toxicity (115), it was found that immunization causes reduced aggregation of tau into PHFs or larger aggregates, and was associated with a reduced behavioral phenotype. However, this also causes an increase of PHF-1 immunoreactivity in the "high-speed soluble" fraction, which in this case would represent any species of GTO size or smaller. This suggests not only that PHFs might be toxic, but also that the soluble species present were not sufficient for toxicity (115).

The inducible pro-aggregation and anti-aggregation mutants of the tau repeat regions created by the Mandelkow laboratory argue against toxicity of soluble tau. In both the cell lines [the study mentioned as evidence against PHF toxicity: (54)], and in the mice $(95,98)$, the common theme was that the anti-aggregation mutant, which would always be a soluble form of tau, was never toxic. The mouse lines provide some additional correlative evidence against toxicity of any form of tau smaller than PHFs, in that the levels of "soluble" tau were constant between the pro-aggregation mouse, which experienced neurotoxicity, and the anti-aggregation mouse, which did not.

Clearly, physiological tau is soluble and non-toxic. However, under pathological conditions tau may undergo changes that render it toxic, even though it may remain soluble.

\section{DISTINGUISHING BETWEEN SMALL (SOLUBLE) TAU OLIGOMERS AND TAU MONOMERS}

In the above paragraphs, a general trend is that the evidence for soluble tau toxicity centers on some reasonably well-defined dimers and trimers which are demonstrably sufficient for toxicity; whereas the evidence against either has not distinguished between the myriad species, or has only said that one particular type of soluble tau 
is not toxic. In that sense, the evidence against is not conclusive. While the specific data cited in favor of dimer and trimer toxicity is compelling, we still know very little about the properties (or indeed existence) of all the other soluble forms.

\section{CONCLUSION}

In conclusion, there is a body of evidence demonstrating that small soluble tau oligomers are the most toxic form of tau. Filamentous and fibrillar tau is neither necessary nor sufficient for tau-induced toxicity, and may very well represent a neuroprotective strategy. Such ideas are not new, and a number of reviews over the past few years have drawn the same conclusions (138-140). Nevertheless, this conclusion is still not broadly accepted. Even if it were to be accepted, many questions remain. We still have little idea which of the multiplicity of soluble tau species is the culprit or culprits: is it monomers, dimers or trimers or all three, and in which conformation(s) and phosphorylation state(s)? Also, we have incomplete information about the sequence of events on the pathway(s) of tau aggregation (Figure 2). Especially, where do GTOs fit in? Are they made gradually from increasing sizes of smaller oligomers? Or do they have a different conformation that makes them so compact and insoluble? Can they really go on to form PHFs in vivo? Such questions are important for informing the strategies to be implemented when developing treatments for $\mathrm{AD}$ and tauopathies. We do not yet know which species of tau would represent the best target for tau-based therapies. If a certain specific set of small soluble tau oligomers are toxic, while insoluble GTOs and larger insoluble tau species are not, then perhaps strategies aimed at breaking up large insoluble tau aggregates might prove ineffective. Especially if it transpires that GTOs are not only non-toxic but on an alternative pathway to PHFs, then perhaps encouraging GTO formation might even turn out to be a valid approach. Alternatively, it might not be size and solubility alone of the tau species that are the

\section{REFERENCES}

1. Goedert M, Spillantini MG. Pathogenesis of the tauopathies. $\mathrm{J} \mathrm{Mol} \mathrm{Neu}$ rosci (2011) 45:425-31. doi:10.1007/s12031-011-9593-4

2. Lee VM, Goedert M, Trojanowski JQ. Neurodegenerative tauopathies. Annu Rev Neurosci (2001) 24:1121-59. doi:10.1146/ annurev.neuro.24.1.1121

3. Goedert M, Jakes R, Crowther RA, Cohen P, Vanmechelen E, Vandermeeren M, et al. Epitope mapping of monoclonal antibodies to the paired helical filaments of Alzheimer's disease: identification of phosphorylation sites in tau protein. Biochem J (1994) 301(Pt 3):871-7.

4. Schweers O, SchonbrunnHanebeck E, Marx A, Mandelkow E. Structural studies of tau protein and Alzheimer paired helical filaments show no evidence for beta-structure. J Biol Chem (1994) 269:24290-7.
5. Chirita CN, Congdon EE, Yin $\mathrm{H}$, Kuret J. Triggers of full-length tau aggregation: a role for partially folded intermediates. Biochemistry (2005) 44:5862-72. doi:10.1021/ bi0500123

6. Schweers O, Mandelkow EM, Biernat J, Mandelkow E. Oxidation of cysteine-322 in the repeat domain of microtubule-associated protein tau controls the in vitro assembly of paired helical filaments. Proc Natl Acad Sci U S A (1995) 92:8463-7. doi:10.1073/ pnas.92.18.8463

7. Wille H, Drewes G, Biernat J, Mandelkow EM, Mandelkow E. Alzheimer-like paired helical filaments and antiparallel dimers formed from microtubuleassociated protein tau in vitro. $J$ Cell Biol (1992) 118:573-84. doi: 10.1083/jcb.118.3.573

8. Sahara N, Maeda S, Murayama M, Suzuki T, Dohmae N, Yen SH, et al. Assembly of two distinct dimers and higher-order oligomers from

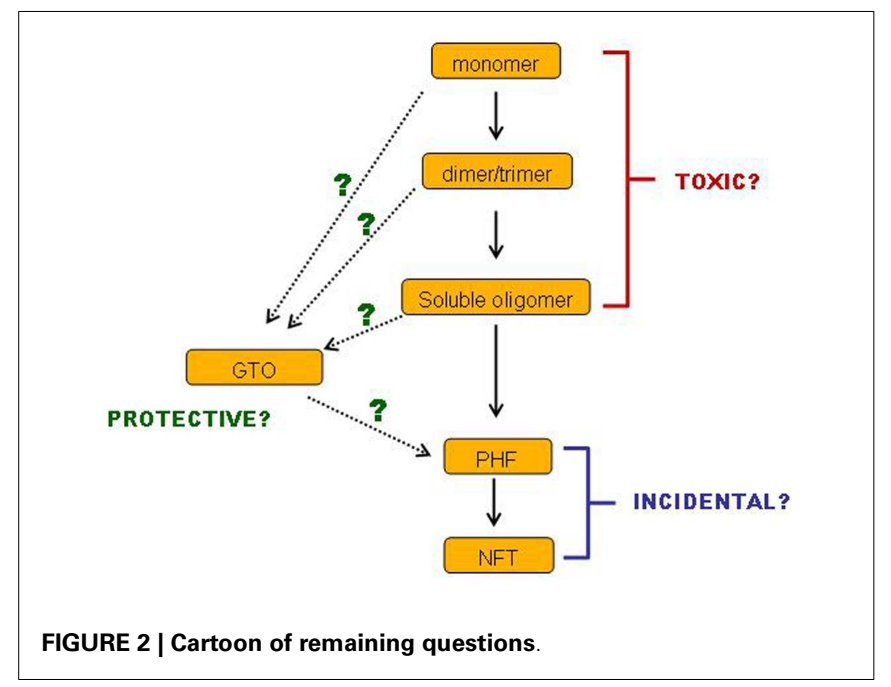

key toxicity-determining factors: levels of $\beta$-sheet structure and phosphorylation at certain sites may also be influential.

There is a precedent from other proteinopathies for a small soluble species being the most toxic, while the smallest insoluble form is relatively protective. This has been demonstrated for huntingtin protein in Hungtington's disease $(141,142)$, alpha-synuclein in Parkinson's disease (143), and amyloid beta in AD (144): however, evidence for this phenomenon in the case of tau aggregation is only beginning to emerge now.

\section{ACKNOWLEDGMENTS}

We would like to thank Dr. Ayodeji A. Asuni (University of Southampton) for reading the manuscript. CMC is funded by a Neurodegenerative Disease Specialist Grant from the Alzheimer's Society and Bupa.

full-length tau. Eur J Neurosci (2007) 25:3020-9. doi:10.1111/j. 1460-9568.2007.05555.x

9. Patterson KR, Remmers C, Fu Y, Brooker S, Kanaan NM, Vana $\mathrm{L}$, et al. Characterization of prefibrillar Tau oligomers in vitro and in Alzheimer disease. I Biol Chem (2011) 286:23063-76. doi: 10.1074/jbc.M111.237974

10. Makrides V, Shen TE, Bhatia R, Smith BL, Thimm J, Lal $\mathrm{R}$, et al. Microtubule-dependent oligomerization of tau. Implications for physiological tau function and tauopathies. $J$ Biol Chem (2003) 278:33298-304. doi: 10.1074/jbc.M305207200

11. Lasagna-Reeves CA, CastilloCarranza DL, Guerrero-Muoz MJ, Jackson GR, Kayed R. Preparation and characterization of neurotoxic tau oligomers. Biochemistry (2010) 49:10039-41. doi:10.1021/bi1016233

12. Berger Z, Roder H, Hanna A, Carlson A, Rangachari V, Yue M, et al.
Accumulation of pathological tau species and memory loss in a conditional model of tauopathy. J Neurosci (2007) 27:3650-62. doi:10. 1523/JNEUROSCI.0587-07.2007

13. Henkins KM, Sokolow S, Miller CA, Vinters HV, Poon WW, Cornwell LB, et al. Extensive ptau pathology and SDS-stable p-tau oligomers in Alzheimer's cortical synapses. Brain Pathol (2012) 22:826-33. doi:10.1111/j. 1750-3639.2012.00598.x

14. Maeda S, Sahara N, Saito Y, Murayama S, Ikai A, Takashima A. Increased levels of granular tau oligomers: an early sign of brain aging and Alzheimer's disease. Neurosci Res (2006) 54:197201. doi:10.1016/j.neures.2005.11. 009

15. Maeda S, Sahara N, Saito Y, Murayama M, Yoshiike Y, Kim H, et al. Granular tau oligomers as intermediates of tau filaments. Biochemistry (2007) 46:3856-61. doi: 10.1021/bi061359o 
16. Campbell BC, McLean CA, Culvenor JG, Gai WP, Blumbergs PC, Jakala P, et al. The solubility of alpha-synuclein in multiple system atrophy differs from that of dementia with Lewy bodies and Parkinson's disease. J Neurochem (2001) 76:87-96. doi:10. 1046/j.1471-4159.2001.00021.x

17. Crowther RA, Goedert M. Abnormal tau-containing filaments in neurodegenerative diseases. J Struct Biol (2000) 130:271-9. doi:10.1006/jsbi.2000.4270

18. Crowther RA, Wischik CM. Image reconstruction of the Alzheimer paired helical filament. $E M B O J$ (1985) 4:3661-5.

19. Ksiezak-Reding H, Morgan K, Mattiace LA, Davies P, Liu WK, Yen $\mathrm{SH}$, et al. Ultrastructure and biochemical composition of paired helical filaments in corticobasal degeneration. Am J Pathol (1994) 145:1496-508.

20. Berriman J, Serpell LC, Oberg KA, Fink AL, Goedert M, Crowther RA. Tau filaments from human brain and from in vitro assembly of recombinant protein show crossbeta structure. Proc Natl Acad Sci U S A (2003) 100:9034-8. doi:10. 1073/pnas. 1530287100

21. Novak M, Kabat J, Wischik CM. Molecular characterization of the minimal protease resistant tau unit of the Alzheimer's disease paired helical filament. EMBO J (1993) 12:365-70.

22. Kosik KS, Orecchio LD, Binder L, Trojanowski JQ, Lee VM, Lee G. Epitopes that span the tau molecule are shared with paired helical filaments. $\mathrm{Neu}$ ron (1988) 1:817-25. doi:10.1016/ 0896-6273(88)90129-8

23. Goedert M. Tau protein and neurodegeneration. Semin Cell Dev Biol (2004) 15:45-9. doi:10.1016/ j.semcdb.2003.12.015

24. von Bergen M, Barghorn S, Biernat J, Mandelkow EM, Mandelkow E. Tau aggregation is driven by a transition from random coil to beta sheet structure. Biochim Biophys Acta (2005) 1739:158-66. doi: 10.1016/j.bbadis.2004.09.010

25. Bancher C, Brunner C, Lassmann $\mathrm{H}$, Budka H, Jellinger K, Wiche G, et al. Accumulation of abnormally phosphorylated tau precedes the formation of neurofibrillary tangles in Alzheimer's disease. Brain Res (1989) 477:90-9. doi:10.1016/ 0006-8993(89)91396-6

26. Hyman BT, Van Hoesen GW, Wolozin BL, Davies P, Kromer LJ, Damasio AR. Alz-50 antibody recognizes Alzheimerrelated neuronal changes. Ann Neurol (1988) 23:371-9. doi:10.1002/ana.410230410

27. Augustinack JC, Schneider A, Mandelkow EM, Hyman BT. Specific tau phosphorylation sites correlate with severity of neuronal cytopathology in Alzheimer's disease. Acta Neuropathol (2002) 103:26-35. doi:10.1007/s004010100423

28. Drewes G, Trinczek B, Illenberger S, Biernat J, Schmitt-Ulms G, Meyer HE, et al. Microtubuleassociated protein/microtubule affinity-regulating kinase (p110mark). A novel protein kinase that regulates taumicrotubule interactions and dynamic instability by phosphorylation at the Alzheimer-specific site serine 262. J Biol Chem (1995) 270:7679-88.

29. Luna-Munoz J, Chavez-Macias L, Garcia-Sierra F, Mena R. Earliest stages of tau conformational changes are related to the appearance of a sequence of specific phospho-dependent tau epitopes in Alzheimer's disease. J Alzheimers Dis (2007) 12:365-75.

30. Friedhoff P, Schneider A, Mandelkow EM, Mandelkow E. Rapid assembly of Alzheimerlike paired helical filaments from microtubule-associated protein tau monitored by fluorescence in solution. Biochemistry (1998) 37:10223-30. doi:10.1021/bi980537d

31. Hirano A. Hirano bodies and related neuronal inclusions. $\mathrm{Neu}$ ropathol Appl Neurobiol (1994) 20:3-11. doi:10.1111/j.1365-2990. 1994.tb00951.x

32. Maciver SK, Harrington CR. Two actin binding proteins, actin depolymerizing factor and cofilin, are associated with Hirano bodies. Neuroreport (1995) 6:1985-8. doi:10.1097/00001756199510010-00008

33. Goedert M. Neurofibrillary pathology of Alzheimer's disease and other tauopathies. Prog Brain Res (1998) 117:287-306. doi:10. 1016/S0079-6123(08)64022-4

34. Tolnay M, Clavaguera F. Argyrophilic grain disease: a late-onset dementia with distinctive features among tauopathies. Neuropathology (2004) 24:269-83. doi:10. 1111/j.1440-1789.2004.00591.x

35. Braak H, Braak E. Argyrophilic grains: characteristic pathology of cerebral cortex in cases of adult onset dementia without
Alzheimer changes. Neurosci Lett (1987) 76:124-7. doi:10.1016/ 0304-3940(87)90204-7

36. Braak H, Braak E. Cortical and subcortical argyrophilic grains characterize a disease associated with adult onset dementia. Neuropathol Appl Neurobiol (1989) 15:13-26. doi:10.1111/j. 1365-2990.1989.tb01146.x

37. Perry G, Kawai M, Tabaton M, Onorato M, Mulvihill P, Richey $\mathrm{P}$, et al. Neuropil threads of Alzheimer's disease show a marked alteration of the normal cytoskeleton. J Neurosci (1991) 11:1748-55

38. Endoh R, Ogawara M, Iwatsubo T, Nakano I, Mori $H$. Lack of the carboxyl terminal sequence of tau in ghost tangles of Alzheimer's disease. Brain Res (1993) 601(1-2):164-72. doi: 10.1016/0006-8993(93)91707-Y

39. von Bergen M, Friedhoff P, Biernat J, Heberle J, Mandelkow EM, Mandelkow E. Assembly of tau protein into Alzheimer paired helical filaments depends on a local sequence motif ((306)VQIVYK(311)) forming beta structure. Proc Natl Acad Sci U S A (2000) 97:5129-34. doi:10.1073/pnas.97. 10.5129

40. Barghorn S, Mandelkow E. Toward a unified scheme for the aggregation of tau into Alzheimer paired helical filaments. Biochemistry (2002) 41:14885-96. doi:10. 1021/bi026469j

41. Kampers T, Friedhoff P, Biernat J, Mandelkow EM, Mandelkow E. RNA stimulates aggregation of microtubule-associated protein tau into Alzheimer-like paired helical filaments. FEBS Lett (1996) 399:344-9. doi:10.1016/ S0014-5793(96)01386-5

42. Montejo de Garcini E, Serrano L, Avila J. Self assembly of microtubule associated protein tau into filaments resembling those found in Alzheimer disease. Biochem Biophys Res Commun (1986) 141:790-6. doi:10. 1016/S0006-291X(86)80242-X

43. Montejo de Garcini E, Avila J. In vitro conditions for the self-polymerization of the microtubule-associated protein, tau factor. J Biochem (1987) 102:1415-21.

44. Montejo de Garcini E, Carrascosa JL, Correas I, Nieto A, Avila J. Tau factor polymers are similar to paired helical filaments of Alzheimer's disease. FEBS Lett (1988) 236:150-4. doi:10.1016/ 0014-5793(88)80304- 1
45. Arrasate M, Perez M, Armas Portela R, Avila J. Polymerization of tau peptides into fibrillar structures. The effect of FTDP17 mutations. FEBS Lett (1999) 446:199-202. doi:10.1016/S00145793(99)00210-0

46. Barghorn S, Zheng-Fischhofer Q, Ackmann M, Biernat J, von Bergen M, Mandelkow EM, et al. Structure, microtubule interactions, and paired helical filament aggregation by tau mutants of frontotemporal dementias. Biochemistry (2000) 39:11714-21. doi:10. 1021/bi000850r

47. von Bergen M, Barghorn S, Li L, Marx A, Biernat J, Mandelkow EM, et al. Mutations of tau protein in frontotemporal dementia promote aggregation of paired helical filaments by enhancing local beta-structure. J Biol Chem (2001) 276:48165-74.

48. Rankin CA, Sun Q, Gamblin TC. Pre-assembled tau filaments phosphorylated by GSK-3b form large tangle-like structures. Neurobiol Dis (2008) 31:368-77. doi:10. 1016/j.nbd.2008.05.011

49. Crowther RA, Olesen OF, Smith MJ, Jakes R, Goedert M. Assembly of Alzheimer-like filaments from full-length tau protein. FEBS Lett (1994) 337:135-8. doi:10. 1016/0014-5793(94)80260-2

50. Avila J, Perez M, Lucas JJ, GomezRamos A, Santa-Maria I, Moreno $F$, et al. Assembly in vitro of tau protein and its implications in Alzheimer's disease. Curr Alzheimer Res (2004) 1:97-101. doi:10.2174/1567205043332207

51. Ugolini G, Cattaneo A, Novak M. Co-localization of truncated tau and DNA fragmentation in Alzheimer's disease neurones. Neuroreport (1997) 8:3709$12 . \quad$ doi:10.1097/00001756199712010-00010

52. McMillan PJ, Kraemer BC, Robinson L, Leverenz JB, Raskind M, Schellenberg G. Truncation of tau at E391 promotes early pathologic changes in transgenic mice. J Neuropathol Exp Neurol (2011) 70:1006-19. doi:10.1097/ NEN.0b013e31823557fb

53. Gamblin TC, Chen F, Zambrano A, Abraha A, Lagalwar S, Guillozet AL, et al. Caspase cleavage of tau: linking amyloid and neurofibrillary tangles in Alzheimer's disease. Proc Natl Acad Sci U S A (2003) 100:10032-7. doi:10.1073/ pnas. 1630428100

54. Khlistunova I, Biernat J, Wang $\mathrm{Y}$, Pickhardt $\mathrm{M}$, von Bergen $\mathrm{M}$, 
Gazova Z, et al. Inducible expression of Tau repeat domain in cell models of tauopathy: aggregation is toxic to cells but can be reversed by inhibitor drugs. J Biol Chem (2006) 281:1205-14. doi:10.1074/ jbc.M507753200

55. Abraha A, Ghoshal N, Gamblin TC, Cryns V, Berry RW, Kuret J, et al. Cterminal inhibition of tau assembly in vitro and in Alzheimer's disease. J Cell Sci (2000) 113(Pt 21):3737-45

56. Berry RW, Abraha A, Lagalwar S, LaPointe N, Gamblin TC, Cryns $\mathrm{VL}$, et al. Inhibition of tau polymerization by its carboxy-terminal caspase cleavage fragment. Biochemistry (2003) 42:8325-31. doi: 10.1021/bi027348m

57. Watanabe A, Takio K, Ihara Y. Deamidation and isoaspartate formation in smeared tau in paired helical filaments. Unusual properties of the microtubule-binding domain of tau. J Biol Chem (1999) 274:7368-78. doi:10.1074/jbc.274. 11.7368

58. Spires-Jones TL, Stoothoff WH, de Calignon A, Jones PB, Hyman BT. Tau pathophysiology in neurodegeneration: a tangled issue. Trends Neurosci (2009) 32:150-9. doi:10. 1016/j.tins.2008.11.007

59. Grundke-Iqbal I, Iqbal K, Tung YC, Quinlan M, Wisniewski HM, Binder LI. Abnormal phosphorylation of the microtubuleassociated protein tau (tau) in Alzheimer cytoskeletal pathology. Proc Natl Acad Sci U S A (1986) 83: 4913-7. doi:10.1073/pnas.83.13. 4913

60. Alonso A, Zaidi T, Novak M, Grundke-Iqbal I, Iqbal K. Hyperphosphorylation induces selfassembly of tau into tangles of paired helical filaments/straight filaments. Proc Natl Acad Sci $\begin{array}{lllll}U & S & A & \text { (2001) 98:6923-8. }\end{array}$ doi:10.1073/pnas.121119298

61. Wang YP, Biernat J, Pickhardt M, Mandelkow E, Mandelkow EM. Stepwise proteolysis liberates tau fragments that nucleate the Alzheimer-like aggregation of full-length tau in a neuronal cell model. Proc Natl Acad Sci U S A (2007) 104:10252-7. doi:10.1073/ pnas.0703676104

62. Sato S, Tatebayashi Y, Akagi T, Chui DH, Murayama M, Miyasaka T, et al. Aberrant tau phosphorylation by glycogen synthase kinase-3beta and JNK3 induces oligomeric tau fibrils in COS-7 cells. J Biol Chem (2002) 277:42060-5. doi:10.1074/ jbc.M202241200
63. Haase C, Stieler JT, Arendt T, Holzer M. Pseudophosphorylation of tau protein alters its ability for self-aggregation. J Neurochem (2004) 88:1509-20. doi:10.1046/j. 1471-4159.2003.02287.x

64. Alonso Adel C, Mederlyova A, Novak M, Grundke-Iqbal I, Iqbal K. Promotion of hyperphosphorylation by frontotemporal dementia tau mutations. J Biol Chem (2004) 279:34873-81. doi: 10.1074/jbc.M405131200

65. Jackson GR, Wiedau-Pazos M, Sang TK, Wagle N, Brown CA, Massachi S, et al. Human wildtype tau interacts with wingless pathway components and produces neurofibrillary pathology in Drosophila. Neuron (2002) 34:509-19. doi:10.1016/S08966273(02)00706-7

66. Noble W, Olm V, Takata K, Casey E, Mary O, Meyerson J, et al. Cdk5 is a key factor in tau aggregation and tangle formation in vivo. Neuron (2003) 38:555-65. doi:10. 1016/S0896-6273(03)00259-9

67. Goedert M. Tau protein and the neurofibrillary pathology of Alzheimer's disease. Ann N Y Acad Sci (1996) 777:121-31. doi:10. 1111/j.1749-6632.1996.tb34410.x

68. Schneider A, Biernat J, von Bergen M, Mandelkow E, Mandelkow EM. Phosphorylation that detaches tau protein from microtubules (Ser262, Ser214) also protects it against aggregation into Alzheimer paired helical filaments. Biochemistry (1999) 38:3549-58. doi:10.1021/bi981874p

69. Kfoury N, Holmes BB, Jiang $H$, Holtzman DM, Diamond MI Trans-cellular propagation of Tau aggregation by fibrillar species. $J$ Biol Chem (2012) 287:19440-51. doi:10.1074/jbc.M112.346072

70. Guo JL, Lee VM. Neurofibrillary tangle-like tau pathology induced by synthetic tau fibrils in primary neurons over-expressing mutant tau. FEBS Lett (2013) 587:717-23. doi:10.1016/j.febslet.2013.01.051

71. Lewis J, McGowan E, Rockwood J, Melrose H, Nacharaju P, Van Slegtenhorst M, et al. Neurofibrillary tangles, amyotrophy and progressive motor disturbance in mice expressing mutant (P301L) tau protein. Nat Genet (2000) 25:4025. doi:10.1038/78078

72. Terwel D, Lasrado R, Snauwaert J, Vandeweert E, Van Haesendonck C, Borghgraef $\mathrm{P}$, et al. Changed conformation of mutant TauP301L underlies the moribund tauopathy, absent in progressive, nonlethal axonopathy of Tau$4 \mathrm{R} / 2 \mathrm{~N}$ transgenic mice. J Biol Chem (2005) 280:3963-73. doi: 10 . 1074/jbc.M409876200

73. Götz J, Deters N, Doldissen A, Bokhari L, Ke Y, Wiesner A, et al. A decade of tau transgenic animal models and beyond. Brain Patho (2007) 17:91-103. doi:10.1111/j. 1750-3639.2007.00051.x

74. Perez M, Valpuesta JM, Medina M, Montejo de Garcini E, Avila J. Polymerization of tau into filaments in the presence of heparin: the minimal sequence required for tau-tau interaction. J Neurochem (1996) 67:1183-90. doi:10.1046/j. 1471-4159.1996.67031183.x

75. Goedert M, Jakes R, Spillantini MG, Hasegawa M, Smith MJ, Crowther RA. Assembly of microtubule-associated protein tau into Alzheimer-like filaments induced by sulphated glycosaminoglycans. Nature (1996) 383:550-3. doi:10.1038/383550a0

76. Arrasate M, Perez M, Valpuesta JM, Avila J. Role of glycosaminoglycans in determining the helicity of paired helical filaments. Am J Pathol (1997) 151:1115-22.

77. Wilson DM, Binder LI. Free fatty acids stimulate the polymerization of tau and amyloid beta peptides. In vitro evidence for a common effector of pathogenesis in Alzheimer's disease. Am J Patho (1997) 150:2181-95.

78. Gamblin TC, King ME, Kuret J, Berry RW, Binder LI. Oxidative regulation of fatty acid-induced tau polymerization. Biochemistry (2000) 39:14203-10. doi:10.1021/ bi0018761

79. Chirita CN, Necula M, Kuret J. Anionic micelles and vesicles induce tau fibrillization in vitro. J Biol Chem (2003) 278:25644-50. doi:10.1074/jbc.M301663200

80. Tucholski J, Kuret J, Johnson GV. Tau is modified by tissue transglutaminase in situ: possible functional and metabolic effects of polyamination. J Neurochem (1999) 73:1871-80.

81. Bandyopadhyay B, Li G, Yin H, Kuret J. Tau aggregation and toxicity in a cell culture model of tauopathy. $J$ Biol Chem (2007) 282:16454-64. doi:10.1074/jbc.M700192200

82. Perez M, Valpuesta JM, de Garcini EM, Quintana C, Arrasate M, Lopez Carrascosa JL, et al. Ferritin is associated with the aberrant tau filaments present in progressive supranuclear palsy. Am J Pathol (1998) 152:1531-9.
83. Troncoso JC, Costello A, Watson AL Jr, Johnson GV. In vitro polymerization of oxidized tau into filaments. Brain Res (1993) 613:313-6. doi:10.1016/00068993(93)90918-D

84. Santa-Maria I, Hernandez F, Martin CP, Avila J, Moreno FJ. Quinones facilitate the selfassembly of the phosphorylated tubulin binding region of tau into fibrillar polymers. Biochemistry (2004) 43:2888-97. doi:10.1021/bi035345j

85. Clavaguera F, Bolmont T, Crowther RA, Abramowski D, Frank S, Probst A, et al. Transmission and spreading of tauopathy in transgenic mouse brain. Nat Cell Biol (2009) 11:909-13. doi:10.1038/ncb1901

86. Tomlinson BE, Blessed G, Roth M. Observations on the brains of demented old people. J Neurol Sci (1970) 11:205-42. doi:10.1016/ 0022-510X(70)90063-8

87. Braak H, Braak E. Neuropathological stageing of Alzheimerrelated changes. Acta Neuropathol (1991) 82:239-59. doi:10.1007/ BF00308809

88. Arriagada PV, Growdon JH, Hedley-Whyte ET, Hyman BT. Neurofibrillary tangles but not senile plaques parallel duration and severity of Alzheimer's disease. Neurology (1992) 42:631-9. doi:10.1212/WNL.42.3.631

89. Dickson DW, Crystal HA, Bevona C, Honer W, Vincent I, Davies P. Correlations of synaptic and pathological markers with cognition of the elderly. Neurobiol Aging (1995) 16:285-98. doi:10. 1016/0197-4580(95)00013-5 discussion 298-304,

90. Nagy Z, Esiri MM, Jobst KA, Morris $\mathrm{JH}$, King $\mathrm{EM}, \mathrm{McD}$ onald $\mathrm{B}$, et al. Relative roles of plaques and tangles in the dementia of Alzheimer's disease: correlations using three sets of neuropathological criteria. Dementia (1995) 6:21-31.

91. Gomez-Isla T, Hollister R, West H, Mui S, Growdon JH, Petersen RC, et al. Neuronal loss correlates with but exceeds neurofibrillary tangles in Alzheimer's disease. Ann Neurol (1997) 41:17-24. doi:10.1002/ana. 410410106

92. Grober E, Dickson D, Sliwinski MJ, Buschke $\mathrm{H}$, Katz M, Crystal $\mathrm{H}$, et al. Memory and mental status correlates of modified Braak staging. Neurobiol Aging (1999) 20:573-9. doi:10. 1016/S0197-4580(99)00063-9 
93. Götz J, Chen F, Barmettler R, Nitsch RM. Tau filament formation in transgenic mice expressing P301L tau. J Biol Chem (2001) 276:529-34. doi:10.1074/ jbc.M006531200

94. Noble W, Planel E, Zehr C, Olm V, Meyerson J, Suleman F, et al. Inhibition of glycogen synthase kinase- 3 by lithium correlates with reduced tauopathy and degeneration in vivo. Proc Natl Acad Sci US A (2005) 102:6990-5. doi:10.1073/ pnas.0500466102

95. Mocanu MM, Nissen A, Eckermann K, Khlistunova I, Biernat J, Drexler D, et al. The potential for beta-structure in the repeat domain of tau protein determines aggregation, synaptic decay, neuronal loss, and coassembly with endogenous Tau in inducible mouse models of tauopathy. J Neurosci (2008) 28:737-48. doi:10.1523/ JNEUROSCI.2824-07.2008

96. Eckermann K, Mocanu MM, Khlistunova I, Biernat J, Nissen A, Hofmann A, et al. The beta-propensity of Tau determines aggregation and synaptic loss in inducible mouse models of tauopathy. $J$ Biol Chem (2007) 282:31755-65. doi: 10.1074/jbc.M705282200

97. Fatouros C, Pir GJ, Biernat J, Koushika SP, Mandelkow E, Mandelkow EM, et al. Inhibition of tau aggregation in a novel Caenorhabditis elegans model of tauopathy mitigates proteotoxicity. $\mathrm{Hum} \mathrm{Mol}$ Genet (2012) 21:3587-603. doi:10. 1093/hmg/dds 190

98. Sydow A, Van der Jeugd A, Zheng F, Ahmed T, Balschun D, Petrova $\mathrm{O}$, et al. Tau-induced defects in synaptic plasticity, learning, and memory are reversible in transgenic mice after switching off the toxic Tau mutant. J Neurosci (2011) 31:2511-25. doi:10.1523/ JNEUROSCI.5245-10.2011

99. Van der Jeugd A, Hochgrafe K, Ahmed T, Decker JM, Sydow A, Hofmann A, et al. Cognitive defects are reversible in inducible mice expressing proaggregant full-length human Tau. Acta Neuropathol (2012) 123: 787-805. doi:10.1007/s00401012-0987-3

100. Williams DW, Tyrer M, Shepherd D. Tau and tau reporters disrupt central projections of sensory neurons in Drosophila. J Comp Neurol (2000) 428:630-40. doi:10. 1002/1096-9861(20001225)428: $4<630:: A I D-C N E 4>3.0 . C O ; 2-\mathrm{X}$
101. Wittmann CW, Wszolek MF, Shulman JM, Salvaterra PM, Lewis J, Hutton M, et al. Tauopathy in Drosophila: neurodegeneration without neurofibrillary tangles. Science (2001) 293:711-4. doi:10. 1126/science. 1062382

102. Mudher A, Shepherd D, Newman TA, Mildren P, Jukes JP, Squire A, et al. GSK-3beta inhibition reverses axonal transport defects and behavioural phenotypes in Drosophila. Mol Psychiatry (2004) 9:522-30. doi:10.1038/ sj.mp. 4001483

103. Mershin A, Pavlopoulos E, Fitch O, Braden BC, Nanopoulos DV, Skoulakis EM. Learning and memory deficits upon TAU accumulation in Drosophila mushroom body neurons. Learn Mem (2004) 11(3):277-87. doi:10.1101/ $\operatorname{lm} .70804$

104. Kosmidis S, Grammenoudi S, Papanikolopoulou K, Skoulakis EM. Differential effects of Tau on the integrity and function of neurons essential for learning in Drosophila. J Neurosci (2010) 30(2):464-77. doi:10.1523/ JNEUROSCI.1490-09.2010

105. Andorfer C, Acker CM, Kress Y, Hof PR, Duff K, Davies P. Cell-cycle reentry and cell death in transgenic mice expressing nonmutant human tau isoforms. J Neurosci (2005) 25:5446-54. doi:10.1523/JNEUROSCI.463704.2005

106. Ishihara T, Hong M, Zhang B, Nakagawa Y, Lee MK, Trojanowski JQ, et al. Age-dependent emergence and progression of a tauopathy in transgenic mice overexpressing the shortest human tau isoform. Neuron (1999) 24:751-62. doi:10. 1016/S0896-6273(00)81127-7

107. Ishihara $T$, Zhang $B$, Higuchi M, Yoshiyama Y, Trojanowski JQ, Lee VM. Age-dependent induction of congophilic neurofibrillary tau inclusions in tau transgenic mice. Am J Pathol (2001) 158:555-62. doi:10.1016/ S0002-9440(10)63997-1

108. Santacruz K, Lewis J, Spires T, Paulson J, Kotilinek L, Ingelsson $\mathrm{M}$, et al. Tau suppression in a neurodegenerative mouse model improves memory function. Science (2005) 309:476-81. doi:10. 1126/science.1113694

109. Spires TL, Orne JD, SantaCruz K, Pitstick R, Carlson GA, Ashe KH, et al. Region-specific dissociation of neuronal loss and neurofibrillary pathology in a mouse model of tauopathy. Am J Pathol (2006)
168:1598-607. doi:10.2353/ajpath. 2006.050840

110. Le Corre S, Klafki HW, Plesnila $\mathrm{N}$, Hubinger $\mathrm{G}$, Obermeier $\mathrm{A}$, Sahagun $\mathrm{H}$, et al. An inhibitor of tau hyperphosphorylation prevents severe motor impairments in tau transgenic mice. Proc Natl Acad Sci U S A (2006) 103:9673-8. doi:10.1073/pnas.0602913103

111. Fox LM, William CM, Adamowicz DH, Pitstick R, Carlson GA Spires-Jones TL, et al. Soluble tau species, not neurofibrillary aggregates, disrupt neural system integration in a tau transgenic model. J Neuropathol Exp Neurol (2011) 70:588-95. doi:10.1097/ NEN.0b013e318220a658

112. Horowitz PM, Patterson KR, Guillozet-Bongaarts AL, Reynolds MR, Carroll CA, Weintraub ST, et al. Early N-terminal changes and caspase- 6 cleavage of tau in Alzheimer's disease. J Neurosci (2004) 24:7895-902. doi:10.1523/ JNEUROSCI.1988-04.2004

113. Morsch R, Simon W, Coleman PD. Neurons may live for decades with neurofibrillary tangles. J Neuropathol Exp Neurol (1999) 58:188-97. doi:10.1097/ 00005072-199902000-00008

114. Wu TH, Lu YN, Chuang CL, Wu CL, Chiang AS, Krantz DE, et al. Loss of vesicular dopamine release precedes tauopathy in degenerative dopaminergic neurons in a Drosophila model expressing human tau. Acta Neuropathol (2013) 125:711-25. doi:10.1007/ s00401-013-1105-x

115. Asuni AA, Boutajangout A, Quartermain D, Sigurdsson EM. Immunotherapy targeting pathological tau conformers in a tangle mouse model reduces brain pathology with associated functional improvements. J Neurosci (2007) 27:9115-29. doi:10.1523/ JNEUROSCI.2361-07.2007

116. LaPointe NE, Morfini G, Pigino G, Gaisina IN, Kozikowski AP, Binder LI, et al. The amino terminus of tau inhibits kinesin-dependent axonal transport: implications for filament toxicity. J Neurosci Res (2009) 87:440-51. doi:10.1002/jnr. 21850

117. Kanaan NM, Morfini GA, LaPointe NE, Pigino GF, Patterson KR, Song Y, et al. Pathogenic forms of tau inhibit kinesin-dependent axonal transport through a mechanism involving activation of axonal phosphotransferases. J Neurosci (2011) 31:9858-68. doi:10.1523/ JNEUROSCI.0560-11.2011
118. Kraemer BC, Zhang B, Leverenz JB, Thomas JH, Trojanowski JQ, Schellenberg GD. Neurodegeneration and defective neurotransmission in a Caenorhabditis elegans model of tauopathy. Proc Natl Acad Sci U S A (2003) 100:9980-5. doi: 10.1073/pnas. 1533448100

119. Spittaels K, Van den Haute C, Van Dorpe J, Geerts H, Mercken $\mathrm{M}$, Bruynseels $\mathrm{K}$, et al. Glycogen synthase kinase-3beta phosphorylates protein tau and rescues the axonopathy in the central nervous system of human four-repeat tau transgenic mice. J Biol Chem (2000) 275:41340-9. doi:10.1074/ jbc.M006219200

120. Honson NS, Jensen JR, Abraha A, Hall GF, Kuret J. Small-molecule mediated neuroprotection in an in situ model of tauopathy. Neurotox Res (2009) 15:274-83. doi:10. 1007/s12640-009-9028-y

121. Alonso Adel C, Li B, GrundkeIqbal I, Iqbal K. Polymerization of hyperphosphorylated tau into filaments eliminates its inhibitory activity. Proc Natl Acad Sci U S A (2006) 103:8864-9. doi:10.1073/ pnas.0603214103

122. Ramsden M, Kotilinek L, Forster C, Paulson J, McGowan E, SantaCruz K, et al. Age-dependent neurofibrillary tangle formation, neuron loss, and memory impairment in a mouse model of human tauopathy (P301L). J Neurosci (2005) 25:10637-47. doi:10.1523/ JNEUROSCI.3279-05.2005

123. Pritchard SM, Dolan PJ, Vitkus A, Johnson GV. The toxicity of tau in Alzheimer disease: turnover, targets and potential therapeutics. J Cell Mol Med (2011) 15:162135. doi:10.1111/j.1582-4934.2011. 01273.x

124. Tai HC, Serrano-Pozo A, Hashimoto T, Frosch MP, SpiresJones TL, Hyman BT. The synaptic accumulation of hyperphosphorylated tau oligomers in Alzheimer disease is associated with dysfunction of the ubiquitin-proteasome system. Am J Pathol (2012) 181:1426-35. doi:10.1016/j.ajpath.2012.06.033

125. Cowan CM, Hands S, Allan DW, Mudher A. $A D / P D$ (2013). Available from: http://adpd.ekonnect.co/ADPD_ 443/poster_51924/program.aspx

126. Ali YO, Ruan K, Zhai RG. NMNAT suppresses tau-induced neurodegeneration by promoting clearance of hyperphosphorylated tau oligomers in a Drosophila model of tauopathy. Hum Mol Genet 
(2012) 21:237-50. doi:10.1093/ hmg/ddr449

127. Shahani N, Subramaniam S, Wolf T, Tackenberg C, Brandt R. Tau aggregation and progressive neuronal degeneration in the absence of changes in spine density and morphology after targeted expression of Alzheimer's diseaserelevant tau constructs in organotypic hippocampal slices. J Neurosci (2006) 26:6103-14. doi:10. 1523/JNEUROSCI.4245-05.2006

128. Gomez-Ramos A, DiazHernandez M, Cuadros R, Hernandez F, Avila J. Extracellular tau is toxic to neuronal cells. FEBS Lett (2006) 580:4842-50. doi:10.1016/j.febslet.2006.07.078

129. Gomez-Ramos A, DiazHernandez M, Rubio A, MirasPortugal MT, Avila J. Extracellular tau promotes intracellular calcium increase through M1 and M3 muscarinic receptors in neuronal cells. Mol Cell Neurosci (2008) 37: 673-81. doi:10.1016/j.mcn.2007. 12.010

130. Cowan CM, Bossing T, Page A, Shepherd D, Mudher A. Soluble hyper-phosphorylated tau causes microtubule breakdown and functionally compromises normal tau in vivo. Acta Neuropathol (2010) 120:593-604. doi:10.1007/s00401010-0716-8

131. Kimura T, Yamashita S, Fukuda T, Park JM, Murayama M, Mizoroki $\mathrm{T}$, et al. Hyperphosphorylated tau in parahippocampal cortex impairs place learning in aged mice expressing wild-type human tau.
EMBO J (2007) 26:5143-52. doi: 10.1038/sj.emboj.7601917

132. Taniguchi T, Doe N, Matsuyama S, Kitamura Y, Mori H, Saito N, et al. Transgenic mice expressing mutant (N279K) human tau show mutation dependent cognitive deficits without neurofibrillary tangle formation. FEBS Lett (2005) 579:5704-12. doi:10.1016/ j.febslet.2005.09.047

133. Kopeikina KJ, Carlson GA, Pitstick R, Ludvigson AE, Peters A, Luebke JI, et al. Tau accumulation causes mitochondrial distribution deficits in neurons in a mouse model of tauopathy and in human Alzheimer's disease brain. Am J Pathol (2011) 179:2071-82. doi:10. 1016/j.ajpath.2011.07.004

134. O'Leary JC III, Li Q, Marinec P, Blair LJ, Congdon EE, Johnson AG, et al. Phenothiazine-mediated rescue of cognition in tau transgenic mice requires neuroprotection and reduced soluble tau burden. $\mathrm{Mol}$ Neurodegener (2010) 5:45. doi:10. 1186/1750-1326-5-45

135. Patterson KR, Ward SM, Combs B, Voss K, Kanaan NM, Morfini $\mathrm{G}$, et al. Heat shock protein 70 prevents both tau aggregation and the inhibitory effects of preexisting tau aggregates on fast axonal transport. Biochemistry (2011) 50:10300-10. doi:10.1021/ bi2009147

136. Lasagna-Reeves CA, CastilloCarranza DL, Sengupta U, Clos AL, Jackson GR, Kayed R. Tau oligomers impair memory and induce synaptic and mitochondrial dysfunction in wild-type mice. Mol Neurodegener (2011) 6:39. doi:10.1186/1750-1326-6-39

137. Lasagna-Reeves CA, CastilloCarranza DL, Sengupta U, Sarmiento J, Troncoso J, Jackson GR, et al. Identification of oligomers at early stages of tau aggregation in Alzheimer's disease. FASEB J (2012) 26:1946-59. doi:10.1096/fj.11-199851

138. Brunden KR, Trojanowski JQ, Lee VM. Evidence that non-fibrillar tau causes pathology linked to neurodegeneration and behavioral impairments. $J$ Alzheimers Dis (2008) 14:393-9.

139. Kayed R. Anti-tau oligomers passive vaccination for the treatment of Alzheimer disease. Hum Vaccin (2010) 6:931-5. doi:10.4161/hv.6. 11.12689

140. Spires-Jones TL, Kopeikina KJ, Koffie RM, de Calignon A, Hyman BT. Are tangles as toxic as they look? I Mo Neurosci (2011) 45:438-44 doi:10.1007/s12031-011-9566-7

141. Steffan JS, Agrawal N, Pallos J, Rockabrand E, Trotman LC, Slepko N, et al. SUMO modification of Huntingtin and Huntington's disease pathology. Science (2004) 304:100-4. doi:10. 1126/science.1092194

142. Arrasate M, Mitra S, Schweitzer ES, Segal MR, Finkbeiner S. Inclusion body formation reduces levels of mutant huntingtin and the risk of neuronal death. Nature (2004) 431:805-10. doi:10.1038/ nature02998
143. Tanaka M, Kim YM, Lee G, Junn E, Iwatsubo T, Mouradian MM. Aggresomes formed by alpha-synuclein and synphilin-1 are cytoprotective. J Biol Chem (2004) 279:4625-31. doi:10.1074/ jbc.M310994200

144. Walsh DM, Selkoe DJ. Oligomers on the brain: the emerging role of soluble protein aggregates in neurodegeneration. Protein Pept Lett (2004) 11:213-28. doi:10. 2174/0929866043407174

Conflict of Interest Statement: The authors declare that the research was conducted in the absence of any commercial or financial relationships that could be construed as a potential conflict of interest.

Received: 13 June 2013; accepted: 29 July 2013; published online: 13 August 2013. Citation: Cowan CM and Mudher A (2013) Are tau aggregates toxic or protective in tauopathies? Front. Neurol. 4:114. doi: 10.3389/fneur.2013.00114

This article was submitted to Frontiers in Neurodegeneration, a specialty of Frontiers in Neurology.

Copyright (c) 2013 Cowan and Mudher. This is an open-access article distributed under the terms of the Creative Commons Attribution License (CC BY). The use, distribution or reproduction in other forums is permitted, provided the original author(s) or licensor are credited and that the original publication in this journal is cited, in accordance with accepted academic practice. No use, distribution or reproduction is permitted which does not comply with these terms. 